\title{
EFFECT OF POSTURAL CONTROL TRAINING AND EDUCATION ON SIT TO STAND TRANSITION AND BALANCE IN STROKE
}

\section{Ishwor Pyatha ${ }^{* 1}$, Murali Sivanandam ${ }^{2}$, Paul Daniel VK ${ }^{3}$, Reshma Lachimasyu ${ }^{4}$.}

${ }^{* 1}$ Student, RV College of Physiotherapy, \#CA 2/83-3, $9^{\text {th }}$ main, $4^{\text {th }}$ Block, Jayanagar, Bangalore, Karnataka, India.

${ }^{2}$ Associate Professor, RV College of Physiotherapy, \#CA 2/83-3, $9^{\text {th }}$ main, $4^{\text {th }}$ Block, Jayanagar, Bangalore, Karnataka, India.

${ }^{3}$ Professor, RV College of Physiotherapy, \#CA 2/83-3, $9^{\text {th }}$ main, $4^{\text {th }}$ Block, Jayanagar, Bangalore, Karnataka, India.

${ }^{4}$ Student, RV College of Physiotherapy, \#CA $2 / 83-3,9^{\text {th }}$ main, $4^{\text {th }}$ Block, Jayanagar, Bangalore, Karnataka, India.

\section{ABSTRACT}

Background: Postural control is defined as the act of maintaining, achieving or restoring a state of balance during any posture or activity. STS is a movement of the body's center of mass (CoM) upward from a sitting position to a standing position without losing balance. STS requires skills, such as coordination between trunk and lower limb movements, muscle strength, control of equilibrium and stability, which is gained from postural control training. The aim is to assess the effect of postural control training and education on sit to stand ability and balance in patients with stroke.

Methods: 40 subjects were trained for postural control by verbal commands and demonstration for correction of their posture. They were trained for 10 days, 5 days a week for 2 weeks. Berg balance scale(BBS) and Five Times Sit to Stand test(FTSTS) were used to measure balance and time required for sit to stand before and after the training.

Results: There was a significant statistical difference with the pre intervention and post intervention in balance $(p=0.001)$ and FTSTS $(p<0.001)$. This demonstrated an overall clinical and statistical improvement in the balance and time to perform sit to stand task after the intervention.

Interpretation and Conclusion: The present study demonstrates the improvement in the sit to stand transition and balance in stroke after the postural control training.

KEY WORDS: Stroke, Balance, Postural control, Sit-to-stand.

Address for correspondence: Ishwor Pyatha, Student, RV College of Physiotherapy, \#CA 2/83-3, $9^{\text {th }}$ main, $4^{\text {th }}$ Block, Jayanagar, Bangalore, Karnataka, India. Phone no.: +919986654260

E-Mail: Ishworldp001@gmail.com

Access this Article online

Quick Response code

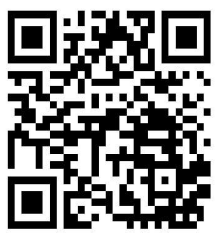

DOI: $10.16965 /$ ijpr.2018.169

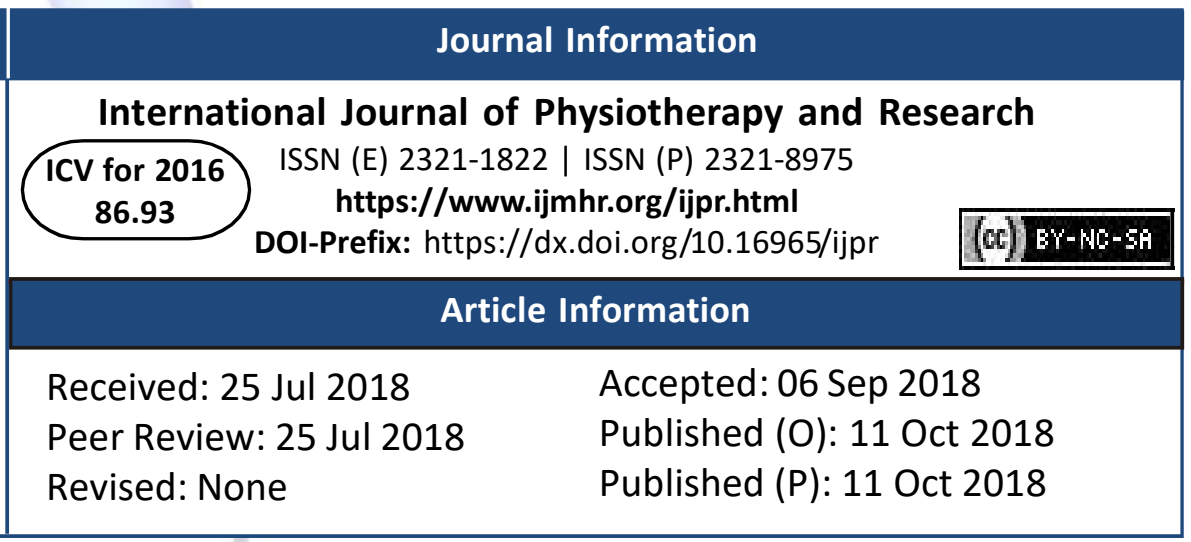

\section{INTRODUCTION}

Sit-to-stand (STS) is performed many times daily and is an important prerequisite to the achievement of many functional goals. Transferring from a sitting to standing position requires large movements, particularly of the hip and the knee [1]. Symmetry, steadiness, and dynamic stability are three elements of postural control. 
Asymmetric dynamic posture and movement is the most prevalent locomotor deficit of strokerelated hemiparesis [2].

The World Health Organization (WHO) defines stroke as "rapidly developing signs of focal (or global) disturbance of cerebral function lasting more than 24 hours (unless interrupted by surgery or death), with no apparent nonvascular cause" [3].

Asymmetric dynamic posture and movement is the most prevalent locomotor deûcit of strokerelated hemiparesis. Postural control strategies may be either predictive or reactive, and may involve either a fixed-support or a changein-support response [4].

Standing up from a seated position is one of the most frequently performed functional tasks, and it is an essential pre-requisite to walking. The ability to stand up without assistance is important for independent living and preventing falls [5]. Deficits related to balance are commonly observed post-stroke, resulting in limitations in activities of daily living. It is known that the postural balance is essential for carrying out daily activities, from the simple, like brushing your teeth, to the most complex, how to move from a sitting to a standing position [6].

Before they can begin to walk, patients with stroke must first stand from being seated and maintain balance. The Center of Mass(COM) must be maintained within the base of support(BOS) during mobility while conducting Activities of Daily Living(ADLs), but most patients have asymmetrical posture, poorly performing extremities, and problems with coordination [7].

The transition point is important because it is when balance parameters change from a stable base of support (sitting) to a relatively unstable base of support (standing). This may be a critical event for understanding prevention of falls in people with stroke.

When the trunk is flexed, the hip extension moment is reduced due to a lack of pelvic anteversion, and patients with stroke may depend primarily on knee extension moment to stand up [8]. The sacral sitting posture with a great degree of spinal flexion and neck extension is frequently observed in patients with stroke. This sitting posture is adopted to prevent falling over backwards due to poor abdominal muscle activation and excessive hip extension [9].

Both balance and postural control are prerequisites for the implementation of sit-to-stand, postural transitions and body functions, understanding the sit to stand ability in stroke survivors may aid better clinical management in mobility contexts of individuals. So, this study aims to find the effect of postural control training during STS and balance in stroke population

\section{METHODS}

Place: All the subjects were trained in RV college of physiotherapy exercise department.

Participants: The subjects were recruited in the study according to the inclusion and exclusion criteria. The subjects were explained about the study and an informed consent was obtained prior to the inclusion of the individuals in the study. All the participants were assessed first using the Five Times Sit-to-Stand test and then balance by Berg Balance test before administering the study intervention. The subjects were explained about the procedure and education was imparted regarding body posture, position of their trunk, head, base of support (BOS), center of gravity (COG) and Center of mass(COM) in the language that the subjects best understand and comprehend. This was followed by postural control training, performance of the movement and repetition of the task. The appropriate patterns of posture and sit to stand transition were explained and demonstrated to the subject prior to making the subject perform the task practice.

The subjects were made to practice the supervised and guided Sit-to-Stand transition for 10 times in each session. The intervention was delivered for five days a week over a period of two weeks. Re-assessment was taken after a period of two weeks to see the effect of the training and education using same outcome measures. The subjects were allowed to continue the regular ongoing rehabilitative therapy and exercises simultaneously.

Statistical analysis: Sample size was determined through power calculation based on previous studies of postural control training in stroke 
population, the sample size 40 is adequate at $90 \%$ statistical power and $5 \%$ level of significance.

The SPSS software (version 16.0) and Excel 2016 was used to analyze all data. Normality of the data was verified using Shapiro Wilk test. The categorical variables are presented with frequency, percentages and graphical representation. Student paired t test has been used to find the significance of study parameters within each group. Significance is assessed at $5 \%$ level of significance with $90 \%$ statistical power.

\section{RESULTS AND DISSCUSSION}

Table 1: Baseline characteristics of the population.

\begin{tabular}{|c|c|c|}
\hline & Mean & $\begin{array}{c}\text { Standard } \\
\text { deviation }\end{array}$ \\
\hline Age & 67.3 & 8.847 \\
\hline Pretest BBS & 35.12 & 5.14 \\
\hline Pretest FTSTS & 69.52 & 29.03 \\
\hline
\end{tabular}

Table 2: Age distribution.

\begin{tabular}{|c|c|c|}
\hline Age in years & Number of Subjects & Percentage \\
\hline $\mathbf{5 0 - 5 9}$ & 12 & 30 \\
\hline $\mathbf{6 0 - 6 9}$ & 11 & 27.5 \\
\hline $\mathbf{7 0 - 7 9}$ & 14 & 35 \\
\hline $\mathbf{8 0 - 8 9}$ & 3 & 7.5 \\
\hline
\end{tabular}

Age distribution

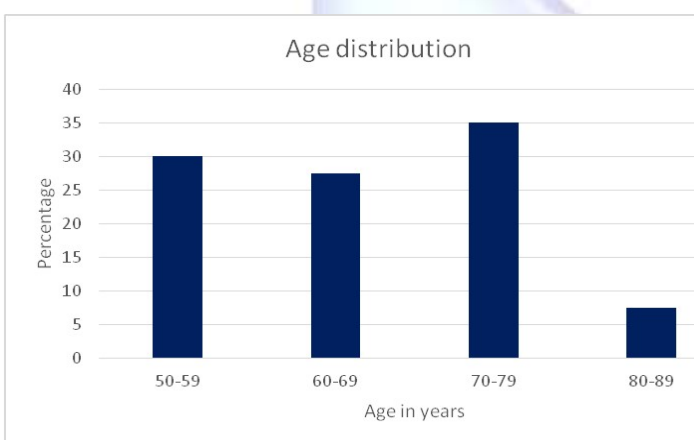

Table 3: Gender distribution.

\begin{tabular}{|c|c|c|}
\hline Gender & Frequency & Percentage \\
\hline Male & 30 & 75 \\
\hline Female & 10 & 25 \\
\hline Total & 40 & 100 \\
\hline
\end{tabular}

Gender distribution

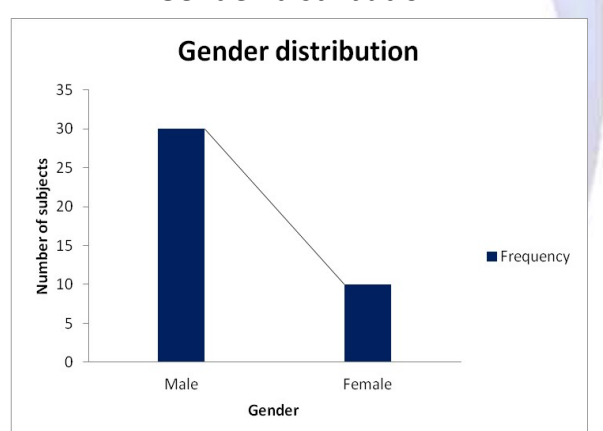

Table 4: Comparison of outcome variables at pre and post evaluation.

\begin{tabular}{|c|c|c|c|c|}
\hline Variables & Pre-test & Post-test & t-value & p-value \\
\hline BBS & $35.12 \pm 5.15$ & $36.22 \pm 9.03$ & -3.704 & $0.001^{*}$ \\
\hline FTSTS & $69.53 \pm 29.04$ & $56.97 \pm 22.08$ & 6.98 & $<0.001^{*}$ \\
\hline
\end{tabular}

Note: BBS-Berg Balance Scale, FTSTS- Five Time Sit to Stand, * indicates statistically significant difference

\section{FTSTS time duration (in seconds) pre and post test}

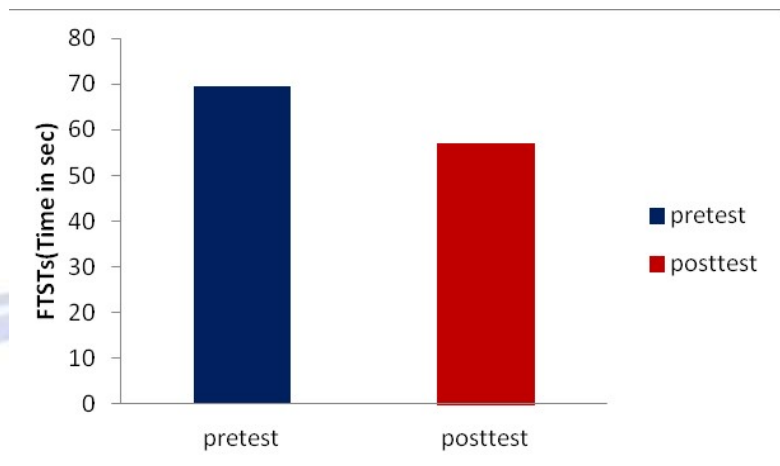

BBS score pre and post test

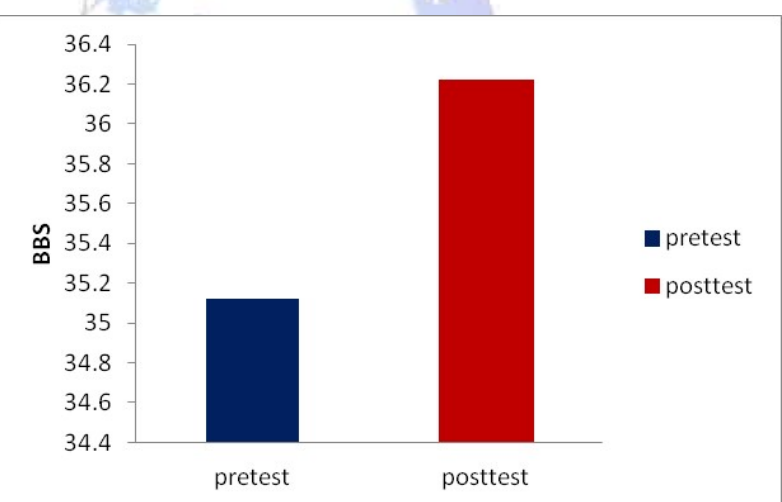

There was a significant statistical difference with the pre intervention and post intervention in both the variables. This demonstrated an overall clinically and statistically improvement in the balance and time to perform sit to stand task after the intervention.

Postural control training helps the subject to align their posture in a correct position so that their COG doesn't change from the normal. STS functional training is an appropriate task for a stroke patient to improve muscle strength and motor control of the affected leg to achieve better gait performance.

This study intends to find the effect of postural control training and education on sit to stand transition and balance in stroke.

The findings of the present study indicate improvement in balance of subject's post intervention. There was improvement in sitting to 
standing, standing unsupported, sitting unsupported, standing to sitting parameters of the outcome measure BBS. This finding is supported by a study done by Chern J.S. et al which concluded that, trunk performance in sitting influences the balance performance in standing and stepping early after stroke [10].

The results suggest significant improvement in STS time post intervention. The results might be attributable to the improve in angular displacements of the lower limbs and trunk, muscular activation pattern of lower limbs, COM transition and symmetrical weight bearing.

The findings of the present study are consistent with the finding of Chow et al. The study has shown the time duration to sit to stand is decreased with asymmetrical weight bearing and also improvement in gait [11].

Another factor to be considered can be visual and auditory feedback. The feedback system will help in motor learning. Postural control training will enhance the motor control over limbs and trunk leading to be more functionally independent. This study did not specify the type and duration of stroke. Acute, sub-acute and chronic all were included. Further studies may be conducted on specific type of stroke population and longer time duration.

\section{CONCLUSION}

This literature review presented the most important factors that affect STS ability in post-stroke individuals. The present study demonstrates the improvement in the sit to stand transition and balance in stroke after the postural control training. This provide the stroke patients confidence to stand and walk. Improvement in balance will further encourage them to perform more dynamic functional activities. Thus postural control training can play an important role in ambulation of the stroke patients.

\section{ABBREVIATIONS}

\author{
BBS- Berg Balance Scale \\ STS- Sit To Stand \\ CoM- Center of Mass \\ CoG- Center of Gravity \\ BOS- Base of Support \\ FTSTSt- Five Times Sit To Stand Test
}

\section{ACKNOWLEDGEMENTS}

I owe my deepest gratitude to all the staffs of RV College of Physiotherapy for their consistent encouragement. My sincere thanks goes to all the subjects for participating in this study.

\section{Conflicts of interest: None}

\section{REFERENCES}

[1]. Roebroeck ME, Doorenbosch CA, Harlaar J, Jacobs R, Lankhorst GJ. Biomechanics and muscular activity during sit-to-stand transfer. Clin Biomech (Bristol Avon) 1994;9:235-44.

[2]. Pollock A, Durward B, Rowe P, Paul J. What is balance? Clinical Rehabilitation. 2000;14(4):402-406.

[3]. Thorvaldsen P, Kuulasmaa K, Rajakangas A, Rastenyte D, Sarti C, Wilhelmsen L. Stroke Trends in the WHO MONICA Project. Stroke. 1997;28(3):500-506.

[4]. Pollock A, Gray C, Culham E, Durward BR, Langhorne $P$. Interventions for improving sit-to-stand ability following stroke._Cochrane Database Syst Rev. 2014;(5):CD007232

[5]. Tyson SF, Hanley M, Chillala J, Selley A, Tallis RC. Balance disability after stroke. Phys Ther. 2006;86(1):30-8

[6]. Pinheiro M, Polere J, Machado G, Scianni A, Hirochi $\mathrm{T}$, Teixiera-Salmela L. Balance analysis during the sit-to-stand movement of chronic hemiparetic individuals based upon their functional levels. MTP Rehabil J. 2014; 12:199

[7]. Titianova E, Pitkanen K, Paakkonen A, Sivenius J, Tarkka I. Gait characterstics and functional ambulation profile in patients with chronic unilateral stroke. Am J Phys Med Rehabil. 2003;82(10):778786.

[8]. Asai H, Tsuchiyama H, Hatakeyama T, Inaoka PT, Murata K.Relationship between the ability to perform the sit-to-stand movement and the maximum pelvic anteversion and retroversion angles in patients with stroke. J Phys Ther Sci. 2015;27(4):985988.

[9]. Davis PM. Problems associated with the loss of selective trunk activity in hemiplegia. In: Right in the middle. New York: Springer-Verlag. 1990:31-65.

[10]. Jen-Suh Chern, Chen-Yu Lo, Ching-Yi Wu, Chia-Ling Chen, Saiwei Yang, Fuk-Tan Tang. Dynamic postural control during trunk bending and reaching in healthy adults and stroke patients. American Journal of Physical Medicine and Rehabilitation. 2010;89(3):186-197

[11]. Chou SW, Wong AMK, Leong CP, Hong WS, Tang FT, Lin TH. Postural Control During Sit-to Stand and Gait in Stroke Patients. Am J Phys Med Rehabil. 2003; 82:42-47. 